\title{
As mídias alternativas ChanacomChana e Lampião da Esquina: uma trajetória de resistência, identidade e visibilidade
}

The alternative media Chanacom Chana and Lampião da Esquina: a trajectory of resistance, identity, and visibility

Los medios alternativos ChanacomChana y Lampião da Esquina: una trayectoria de resistencia, identidad y visibilidade

Eder Ahmad Charaf Eddine

ORCID: https://orcid.org/0000-0003-1882-8503 Universidade Federal do Tocantins, Brasil E-mail: ederahmad@uft.edu.br

Aline de Jesus Sena

ORCID: https://orcid.org/0000-0002-4634-8323 Secretaria Municipal de Educação de São Mateus, Brasil E-mail: letrasaline.ufms@gmail.com

José Eduardo de Azevedo Gomes Rodrigues

ORCID: https://orcid.org/0000-0001-6296-0312

Universidade Federal do Tocantins, Brasil

E-mail: eduardosemed@gmail.com

Thamires Rosa Costa Lima

ORCID: https://orcid.org/0000-0002-2096-3846

Universidade Federal do Tocantins, Brasil E-mail: thamireslima@uft.edu.br

\begin{abstract}
Resumo
Algumas mídias alternativas foram importantes instrumentos de resistência em um Brasil que estava em plena ditadura civil e militar (1964-1985). Vários grupos minoritários foram considerados subversivos e acusados de tentarem contra a moral e os bons costumes. Entre eles pode-se encontrar aqueles formados por gays, lésbicas, travestis e transexuais. Alguns grupos políticos compostos por populações excluídas foram criados para combater essas formas de opressão e para dar visibilidade a suas causas, como o GALF - Grupo de Ação Lésbico-Feminista e o grupo SOMOS. Esse período foi devastador para as questões de liberdades individuais, principalmente para a população e o movimento LGBT. A criação de mídias alternativas como o jornal Lampião da Esquina (1978-1981) e o boletim ChanacomChana (1981-1987), que apresentavam questões relacionadas ao cotidiano, às artes e a política, foi um passo importante na luta para o reconhecimento dessa população. O objetivo desse trabalho é fazer e analisar a revisão narrativa de literatura sobre os dois periódicos, para tanto realizamos a busca nos bancos de dados Scielo, BDTD e Periódicos Capes. Os descritores foram: Lampião da Esquina, Chana com Chana e Chanacomchana. Retornaram 20 teses e dissertações e 20 artigos baseados nesses descritores. Após quantificação e categorização dos resultados observa-se poucos os estudos sobre o boletim ChanacomChana, uma tese e um artigo. As pesquisas elencadas analisam os periódicos como processos de resistências, visibilidade/invisibilidade trans, gay e lésbica, identidades, corpo e literatura.
\end{abstract}

Palavras-chave: Mídia alternativa; Jornal alternativo; Meios de comunicação; Ditadura civil-militar; Militância LGBT.

\begin{abstract}
A variety of alternative media were important tools of resistant in a Brazil that was deep in civil and military dictatorship (1964-1985). Several minority groups were considered subversive and accused of trying to oppose morals and good manners. Among them are those formed by gays, lesbians, transvestites and transsexuals. Some political groups composed of excluded populations were created to withstand against these forms of oppression and to give visibility to its causes, like the GALF - Grupo de Ação Lésbico-Feministas (Group of Action Lesbian-Feminist) and SOMOS group. This period was devastating for issues of individual liberties, especially for the population and the LGBT movement. The creation of alternatives medias like the Lampião da Esquina publications / newspaper (19781981) and the bulletin ChanacomChana (1981-1987), was an important step in the battle for the recognition of such population. These alternatives medias presented questions related to daily life, the arts, and politics. This work aims to make and analyze the narrative review of literature on the two journals, for that purpose we conducted the search in
\end{abstract}


the databases Scielo, BDTD, and Periódicos Capes. The descriptors were: Lampião da Esquina, Chana with Chana and Chanacomchana. Where returned 20 theses and dissertations and 20 articles based on these descriptors. After quantifying and categorizing the results, it is observed that there were few studies on the ChanacomChana bulletin, a thesis and an article. Such works analyze the journals as processes of resistance, trans / gay and lesbian visibility / invisibility, identities, body, and literature.

Keywords: Alternative media; Alternative publications; Means of communication; Civil-militar dictatorship; LGBT militancy.

\section{Resumen}

Algunos medios alternativos fueron importantes instrumentos de resistencia en un Brasil que se encontraba en plena dictadura civil y militar (1964-1985). Se descubrió que varios grupos minoritarios eran subversivos y se los acusó de tratar de oponerse a la moral y los buenos modales. Entre ellos se encuentran los formados por gays, lesbianas, travestis y transexuales. Para combatir estas formas de opresión y dar visibilidad a sus causas se crearon algunos grupos políticos integrados por poblaciones excluidas, como GALF - Grupo de Acción Lésbico-Feminista y el grupo SOMOS. Este período fue devastador para temas de libertades individuales, especialmente para la población y el movimiento LGBT. La creación de medios alternativos como el periódico Lampião da Esquina (1978-1981) y el boletín ChanacomChana (1981-1987), fue un paso importante en la lucha por el reconocimiento de esta población. Estos medios alternativos presentaron preguntas relacionadas con la vida cotidiana, las artes y la política. El objetivo de este trabajo es realizar y analizar la revisión narrativa de la literatura de las dos revistas, para ello realizamos la búsqueda en las bases de datos Scielo, BDTD y Periódicos Capes. Los descriptores fueron: Lampião da Esquina, Chana con Chana y Chanacomchana. Se devolvieron 20 tesis y disertaciones y 20 artículos basados en estos descriptores. Después de cuantificar y categorizar los resultados, se observa que hubo pocos estudios sobre el boletín ChanacomChana, una tesis y un artículo. Las investigaciones enumeradas analizan las revistas como procesos de resistencia, visibilidad/invisibilidad trans, gay y lésbica, identidades, cuerpo y literatura.

Palabras clave: Medios alternativos; Diario alternativo; Medios de comunicación; Dictadura cívico-militar; Militancia LGBT.

\section{Introdução}

Ciclos de repressões, sejam eles religiosos ou políticos, marcam de forma significativa a história da humanidade (Eddine, 2019; Lima \& Eddine, 2015). Não raro, esses momentos vêm acompanhados por movimentos progressistas que atuam como forma de resistência a esses momentos sombrios e buscam mudanças consideradas subversivas dentro de um contexto opressor que é instaurado nesses ciclos repressivos. A ditadura civil e militar no Brasil, que atuou entre os anos de 1964 à 1985, foi um desses ciclos de controle que, entre mortes, exílios e censura, está marcada como um capítulo doloroso na história do País.

Como mecanismo de resistência brasileira atuante nesse contexto aponta-se a imprensa alternativa que exercia atividades jornalísticas consideradas contraventoras para o período. O trabalho desses veículos alternativos ia além do capitalismo e do lucro, objetivos principais dos muitos canais de comunicação atuantes daquela época (Ferreira, 2010). A elaboração, organização e divulgação de conteúdos abominados pelo conservadorismo enraizado, fervorosamente defendido no período da ditadura civil e militar, foi um grande desafio para muitos profissionais que trabalhavam, por exemplo, a pauta homossexual. Mesmo diante de todas as dificuldades apresentadas, há relatos de que circularam, no Brasil, 27 publicações gays entre 1960 e o começo do ano de 1970 (MacRae, 2018). Entre os periódicos brasileiros que se destacavam na questão informacional alternativa da época podem ser citados os jornais "Pasquim (RJ), Opinião (RJ), Movimento (SP), Lampião da Esquina (RJ), Em Tempo (SP), Brasil Mulher (SP), Beijo (RJ), Ex (SP), Versus (SP)” (Brito, 2016, p. 15).

O objetivo do presente artigo é realizar um levantamento narrativo de literatura científica existente sobre os dois periódicos considerados mais importantes na luta dos movimentos gays e lésbicos do período da ditadura civil e militar brasileira, o Jornal Lampião da Esquina e o Boletim Chanacomchana. Para alcançarmos esse objetivo, realizamos a busca nos bancos de dados Scielo, BDTD e Periódicos Capes, com os seguintes descritores: Lampião da Esquina, Chana com Chana e Chanacomchana. A seguir, apresentamos a metodologia que guiou o trabalho e posteriormente uma breve discussão sobre as mídias alternativas gays e sua importância para o movemento no período da década de 1980. 


\section{Metodologia}

O jornal Lampião da Esquina e ChanacomChana se tornaram documentos importantes para a visibilidade homossexual, tanto de homens quanto de mulheres, naquele período que compreende o final da década de 1970 até meado dos anos de 1980. Essa relevância fez com que esses documentos se tornassem ricas fontes de pesquisa utilizadas em trabalhos acadêmicos com as mais distintas abordagens. A pesquisa apresentada nesse artigo, de metodologia quanti e qualitativa, é bibliográfica de revisão narrativa (Pereira et al., 2018). Para a coleta dos dados, utilizamos o levantamento dos documentos científicos existentes sobre os dois periódicos em bases de dados informatizadas para, posteriormente, realizarmos a categorização dos trabalhos científicos encontrados que, de algum modo, utilizaram o jornal e o boletim como objeto de apreciação.

As buscas, realizadas nas plataformas SCIELO, Periódicos CAPES e Biblioteca Digital Brasileira de Teses e Dissertações (BDTD), resultaram em 40 publicações científicas, entre artigos, teses e dissertações. Esses resultados nortearão a quantificação e categorização realizada nesta pesquisa.

O levantamento dessas publicações foi realizado a partir da ferramenta de busca de cada uma das plataformas citadas delimitando o período de 20 anos, de maio de 2000 até maio de 2020, os trabalhos encontrados correspondem aos anos 2006 até 2020. Para filtro das buscas, optamos pela utilização dos termos "Chanacomchana" e "Chana com Chana" e "Lampião da Esquina", que resultaram na quantidade total de trabalhos analisados neste estudo.

\section{Lampião da Esquina e Chanacomchana: Visibilidade e Resistência em Duas Imprensas}

\section{Alternativas}

O jornal carioca Lampião da Esquina se destacou como um instrumento de grande repercussão no contexto da imprensa alternativa do Brasil. Sua produção se voltou de forma mais detida e específica às notícias e informações relacionadas ao público gay. Esse periódico é um dos objetos desta análise.

O Lampião surge no contexto da imprensa alternativa dos movimentos de contracultura das décadas de 1960 e 1970. É considerado o primeiro veículo de distribuição em massa voltado para o debate sobre direito das minorias e, principalmente, da homossexualidade. Sua edição mensal tinha tiragem de 20.000 exemplares. Era uma imprensa altamente especializada, segmentada e militante (Moretti-Pires et al., 2018, p. 3).

O Lampião da Esquina tornou-se um marco de resistência homossexual no período da ditadura civil e militar brasileira. Foi durante esse momento que diversos grupos se organizaram para resistir ao regime civil e militar, entre essas minorias temos as mulheres e os negros. Assim como esses movimentos, as publicações do Lampião da Esquina auxiliaram seu público-alvo com informações de caráter político e serviram como fontes de apoio contra a discriminação e a favor de direitos da comunidade LGBT no País (Ferreira, 2010; Green \& Quinalha, 2015).

As edições do Lampião da Esquina circularam pelo Brasil entre os anos de 1978 e 1981. É importante destacar que a criação do jornal acontece no mesmo ano em que o Ato Institucional $\mathrm{n}^{\circ} 5$ (AI-5), um dos mais severos da ditadura civil e militar brasileira, foi revogado. Era o início de uma abertura política no país rumo à democracia que se consolidou anos mais tarde, com a Constituição Federal de 1988.

A ideia de criar um jornal voltado para o público homossexual da época surgiu após a visita do editor Winston Leyland do jornal gay Sushine, de São Francisco (Neto \& Do Amaral, 2016). Profissionais da área da comunicação, que trabalhavam no Brasil, reuniram-se com o escritor norte-americano e, após debates sobre assuntos que giravam em torno da pauta LGBT, a edição $\mathrm{n}^{\circ} 0$ do Lampião da Esquina foi produzida: 
O jornalista João Antonio Mascarenhas reuniu então um grupo de jornalistas para entrevistar Leyland para o Pasquim. Estes ficaram tão empolgados com a matéria que começaram a discutir a possibilidade de se lançar uma publicação que tratasse de forma séria a homossexualidade, destacando o seu contexto social. Realizaram-se várias reuniões e o grupo foi ampliado, para incluir alguns intelectuais que não haviam participado da reportagem para o Pasquim. As discussões serviram para revelar a existência de grandes diferenças de opinião entre os participantes, mas depois de algum tempo, estes resolveram deixar a teoria e passar à prática, produzindo o número zero, que saiu em abril de 1978 (MacRae, 2018, p. 143).

A produção da primeira edição do Lampião da Esquina, em meio a um período de constante censura e de medo provocados pela ditadura civil e militar, evidenciou a importância e necessidade de ações de resistência diante de tempos sombrios, como era o contexto da época, para a promoção e fortalecimento de debates. Essa necessidade se amplia quando a questão informacional é de interesse de minorias que, frequentemente, são invisibilizadas em diferentes setores, inclusive pelo próprio poder público, por razões distintas. A edição número zero do jornal, que inicialmente chamou-se apenas "Lampião", foi para as bancas em abril 1978 e só a partir da $1^{a}$ edição, por questões autorais, formalizou-se como "Lampião da Esquina" (Da Costa, 2019).

Dentro do contexto de produção editorial do jornal, nos seus mais distintos seguimentos e seções, há destaque para algumas figuras que se mostraram essenciais para que a concretização do projeto acontecesse. Entre os nomes que reconhecidamente devem ser citados nos estudos que envolvem o periódico estão 11 personalidades brasileiras, que, naquela época, já trabalhavam com jornalismo e comunicação e são consideradas fundadoras do Lampião da Esquina. São elas:

- $\quad$ Adão Costa - jornalista, pintor.

- $\quad$ Aguinaldo Silva - jornalista, escritor.

- Antônio Chrysóstomo - jornalista e crítico musical.

- Clóvis Marques - jornalista.

- Darcy Penteado - artista plástico e escritor. Considerado o primeiro intelectual brasileiro a defraudar publicamente a bandeira de luta contra a discriminação e o preconceito em relação aos homossexuais.

- $\quad$ Francisco Bittencourt - poeta, crítico de arte e jornalista.

- Gasparino Damata - jornalista e escritor.

- Jean-Claude Bernardet - crítico de cinema, teórico do Cinema Novo.

- João Antônio Mascarenhas - advogado, jornalista e político que defendeu a proibição da discriminação por orientação sexual na Assembleia Nacional Constituinte de 1987-1988.

- João Silvério Trevisan - cineasta e escritor.

- $\quad$ Peter Fry - antropólogo inglês naturalizado brasileiro (Moretti-Pires et al., 2018, p. 4).

Esses profissionais foram essenciais, cada um em sua respectiva função, para que o Lampião da Esquina fosse produzido e distribuído. Os caminhos trilhados por eles, após o encerramento do jornal, foram os mais diversos. Houve dolorosos casos que ganharam grande repercussão, como o de Antônio Chrysóstomo acusado de pedofilia que, após ser solto pela ausência de provas que comprovassem sua culpa, teve uma morte triste e solitária. Por outro lado, há casos de grandes sucessos, como o autor de novelas Aguinaldo Silva e o escritor do famoso livro Devassos no Paraíso, João Silvério Trevisan.

Esse breve relato histórico acerca da criação do jornal Lampião da Esquina se faz necessário para situar a importância política e social que o mesmo exerceu durante a ditadura civil e militar iniciada na década de 1960. Essa mesma necessidade pode ser ilustrada, também, nas palavras de Alexandre Brito ao afirmar que “[...] pensar as relações entre história e memória é necessário para se entender como o Lampião da Esquina é parte da memória LGBT e da sua resistência durante a ditadura, contribuindo com a visibilidade de sujeitos historicamente silenciados" (Brito, 2016, p. 23).

Entre os diversos meios de resistência utilizados pelo periódico, encontra-se a busca pela ressignificação de palavras utilizadas por pessoas heterossexuais para ridicularizar os homossexuais, como viado, sapatão, bicha entre outras palavras (Da Costa, 2019). Esse método de luta social, o empenho pela redefinição da linguagem, foi de extrema importância e eficácia, visto que "[...] reforçar novas categorias ou identidades não é simplesmente normatizar, mas também pode ser uma tática inteligente de resistência para fazer valer as reivindicações de um discurso geralmente desqualificado" (MacRae, 2018, p. 44). 
A visibilidade social, de qualquer seguimento da sociedade, é extremamente necessária para que haja respeito e garantia de direitos fundamentais. Compreender o contexto em que surgiu o Lampião da Esquina, responsáveis por sua criação e modo de atuação é absolutamente necessário para que se compreenda seu papel de resistência LGBT durante a ditadura civil e militar do Brasil.

O Lampião da Esquina, de corpo editorial exclusivamente masculino, na busca pela garantia de igualdade de espaços, destinou alguns momentos de seus números para as pautas levantadas pelas mulheres lésbicas. Esse tipo de espaço fez aflorar nessas mulheres a urgência em se ter um espaço próprio para que suas pautas pudessem ser atendidas em sua totalidade, algo que não ocorria, segundo elas, no jornal Lampião da Esquina. Essa necessidade fez com que as mulheres lésbicas se organizassem para a produção de um periódico próprio que refletisse a totalidade de seus anseios, assim surge o ChanacomChana.

A luta das mulheres por visibilidade é histórica. Sua existência e importância são apagadas desde sempre, se pensarmos a partir do ponto de vista histórico, por essa razão, suas lutas são sempre constantes e necessárias para que se alcance espaços mais justos nos mais variados seguimentos da sociedade.

É necessário ressaltar que as lutas das mulheres, a depender de sua cor, classe social etc. possuem demandas absolutamente diferentes, pois o contexto em que estão inseridas requer diferentes abordagens e questionamentos.

A urgência de luta por direitos se amplia quando pensada a partir do contexto de uma mulher lésbicas, pois a sexualidade feminina, que ainda hoje se apresenta como um tabu, era totalmente invisibilizado na época da ditadura civil e militar brasileira.

No ocidente, o movimento lésbico emerge em meio às críticas enfrentadas pela segunda onda do movimento feminista da década de 1960, nos EUA. Dentro do movimento não havia a observação das necessidades às questões que eram urgentes para as mulheres lésbicas, assim a segundo onda do feminismo norte-americano trazia pautas que eram excludentes à realidade enfrentada pelas mulheres lésbicas.

Quando esse grupo de mulheres se organizou junto ao movimento gay, na busca por representatividade e voz, observou a presença recorrente do machismo e da misoginia praticados por homens participantes do movimento gay (Oliveira, 2017).

O primeiro tipo de contribuição do movimento lésbico para os outros movimentos sociais não é outro senão lhes permitir se interrogar sobre seus limites e sobre o que não foi pensado tanto nas suas práticas cotidianas quanto nos seus objetivos políticos, muito particularmente no domínio da sexualidade, da família, da divisão sexual do trabalho ou da definição dos papéis masculinos e femininos. (Falquet, 2012, p. 15).

O movimento lésbico se posiciona como um termômetro à dificuldade dos movimentos existentes em abordar as muitas pautas que são caras às mulheres lésbicas. Frente a esses questionamentos surge, no Brasil, durante a ditadura civil e militar, o movimento lésbico que tem objetivo de se opor ao que é imposto e formando, junto a outros movimentos sociais, uma frente de resistência e luta pela democratização e visibilidade desse público.

O jornal Lampião da Esquina permitiu que se falasse abertamente sobre a sexualidade feminina. Pela primeira vez, no número 12 do periódico, sob o título "Amor entre mulheres (elas dizem, onde, quando, como e porquê)", é dado espaço e visibilidade à lesbianidade. Essa publicação trata da sexualidade da mulher lésbica de modo não patologizante ou como destaque das páginas policiais (Oliveira, 2017).

Mulheres pertencentes ao grupo Somos e outras mais, formando um total de 25 lésbicas, foram convidadas a escrever a edição de número 12 do jornal Lampião da Esquina após um ano de sua primeira publicação. Em um total de cinco páginas, foi possível, a esse grupo, falar abertamente sobre lesbofobia, sexualidade e repressão no período da ditadura. Ao justificar a 
demora para que fosse lançada uma publicação com a temática e produção de mulheres lésbicas, elas dizem:

Nós estamos atrasadas porque existimos, mas sempre abdicamos de existir. Existimos nos cochichos, nos bochichos, em algum barzinho, em algumas boates, n'alguma cama com algum corpo, nas fantasias e sonhações que, na maioria das vezes, arquivamos desde sempre. Nós estamos atrasadas porque temos medo, receio, cagaço mesmo de viver o que somos. Porque não construímos o espaço do nosso viver. Porque vivemos na clandestinidade. (...) A repressão perpassa todas as esferas do nosso existir. O fato de sermos mulheres homossexuais duplica a repressão. Além de mulher, ser homossexual é muito, né? Quer ver muito mais? Mulher, negra, homossexual. Quer ver mais? Nós estamos atrasadas porque os valores garantidos pelos esquemas repressivos têm conseguido um desempenho eficaz. (Jornal Lampião Da Esquina, 1979, , ed. 12, p. 7).

Mesmo com o espaço no Lampião da Esquina o preconceito contra mulheres lésbicas ainda habitava a comunidade gay. Não havia espaço necessário para que pautas específicas do público feminino homossexual fossem devidamente debatidas. "Em pouco tempo, as mulheres lésbicas que participavam do Somos sentiram a necessidade de chamar atenção para as especificidades que existiam sobre as lésbicas e sua militância. Em julho de 1979 elas criam o 'LF' - Grupo Lésbico Feminista [...]" (Ire et al., 2019, p. 200).

Vale ressaltar que o próprio movimento lésbico, ainda na época da ditadura civil e militar, sofreu discriminação dentro de ambientes onde o apoio as suas pautas deveriam ocorrer, como no grupo Somos. "As integrantes do LF [...] se sentiam por muitas vezes intimidadas e incomodadas com o machismo presente no grupo por parte de alguns integrantes [...]. Ouviam muito as palavras 'rachas', 'rachadas' em referência às lésbicas em termo pejorativo" (Sales, 2019, p. 26). Dentro da esquerda e do movimento feminista também houve preconceito acerca das pautas das mulheres homossexuais. No entanto, mesmo que essa reflexão seja válida e necessária, é importante destacar que esses espaços foram, posteriormente, agregadores para que as lésbicas se identificassem em suas lutas e resistência (Ire et al., 2019).

Foi a partir desse anseio por mais espaço na divulgação de suas pautas que o movimento lésbico começa a reorganizar-se internamente com o objetivo de lançar um jornal específico para o seu público. É nesse contexto que surge o periódico "ChanacomChana".

Após a separação do grupo Lésbico Feminista do grupo SOMOS, o grupo passou a se identificar como lésbicasfeministas. Um marco dessa nova época do grupo, foi a publicação do Chanacomchana, divulgado inicialmente no formato de jornal, em 1981, porém o grupo se desfez e, surgiu o Grupo de Ação Lésbico Feminista (GALF), tendo como fundadoras Miriam Martinho e Rosely Roth que retomaram a produção do Chanacomchana agora no formato de boletim, de publicação trimestral contendo 12 edições, sendo a primeira do ano de 1982 e a última em 1987. (Sales, 2019, p. 28).

A circulação do ChanacomChana foi um marco para a representatividade lésbica no período da ditadura civil e militar. A repressão, a censura e o medo, causados nesse período da história brasileira, redefiniram a resistência e as lutas travadas pelas mulheres lésbicas do Brasil (Ire et al., 2019).

ChanacomChana foi um pulo do conformismo para a participação. Nosso jornal é nossa ponte. A palavra CHANA não pode ser sumariamente definida como "orgão sexual feminino". É algo tão mais amplo, quanto os contrapontos a existir. Que a palavra CHANA soe para uns como "CHANCE"; para outros como "CHANCA" (pé grande - sapatão?), e para outros como "CHAMA". O importante é isentar-se das conotações. [...] sabemos que CHANACOMCHANA é um sopro, mas há horas em que um sopro pode representar tudo, inclusive a vida. E a vida é negra, é prostituta, é homossexual, é mulher, e amamos todas as suas facetas politicamente minoritárias. (Jornal Chanacomchana, 1981, p. 4).

As lesbianas do boletim ChanacomChana utilizam a palavra CHANA com o propósito de ressignificação do termo e, a ele, atribuem outros sentidos. Ao se apropriarem dessa palavra, comumente utilizada para insultar e menosprezar, são 
capazes de inserir sentidos políticos, de ideias, sentimentos e expressões que trabalham para o fim da desvalorização de sua sexualidade por serem mulheres homossexuais (Lessa, 2009). Nesse caminho, o boletim se tornou de extrema relevância para a promoção da visibilidade da mulher lésbica brasileira. As edições do periódico refletem as pautas e dificuldades enfrentadas pelas leitoras acerca de temas que permanecem até os dias atuais, como: família, maternidade, política, sexualidade e trabalho. Ao todo, foram publicadas 12 edições do boletim dentro de um período que vai de 1982 a 1987.

O boletim ChanacomChana se mostra como parte importante da segunda geração da imprensa feminista no Brasil, pois é nesse momento que se desvincula de partidos políticos e movimentos semelhantes. O boletim é um dos responsáveis pela fortificação e criação de novas identidades pelo Grupo de Ação Lésbica-Feminina (GALF). As pautas levantadas atendiam as necessidades mais diversas, mas preconizavam pelo recorte político da lesbianidade em suas abordagens (Campos, 2014). Campos ainda ressalta em sua pesquisa que "[...] a visibilidade é fundamental como afirmação da existência de uma parcela da população que possui especificidades a serem atendidas" (Campos, 2014, p. 21) e, quando esta é alcançada, permite a garantia e manutenção de direitos fundamentais que já é dada aos demais cidadãos.

O boletim ChanacomChana traz a quebra de estereótipos e promove uma escrita participativa com as leitoras opinando e contribuindo na escrita do mesmo. Esse processo tira as mulheres lésbicas da clandestinidade e desmistifica interpretações equivocadas que são permitidas pela invisibilidade do grupo. Com o ChanacomChana houve a possibilidade de “[...] quebrar o muro de preconceitos que envolve e isola as mulheres lésbicas, criando uma rede de contatos, informações e apoio tanto no Brasil quanto no exterior" (Boletim Chanacomchana, 1987).

Além de todo esse debate político foi possível, a partir do periódico, que fossem estabelecidas relações de amizades e amorosas por meio de interações que se iniciaram nos espaços das publicações. Assim, o ChanacomChana tem a sua importância social nivelada ao Lampião da Esquina, porém voltada para a comunidade lésbica.

\section{Resultados e Discussão}

Nos Quadros 1, 2, 3, 4 e 5, são ilustradas e quantificadas todas as respostas encontradas a partir dos termos buscados. Para critério de organização e melhor visualização, os trabalhos foram separados por plataforma de hospedagem. Como observa-se logo abaixo:

Quadro 1 - Artigos encontrados nas plataformas SCIELO e Periódicos CAPES.

\begin{tabular}{|c|c|c|}
\hline Termo de busca & SCIELO & Periódico CAPES \\
\hline $\begin{array}{c}\text { Chanacomchana ou } \\
\text { Chana com Chana }\end{array}$ & 0 & 1 \\
\hline Lampião da Esquina & 04 & 15 \\
\hline Total & 04 & 16 \\
\hline
\end{tabular}

Pesquisas realizadas nas plataformas Scielo e Periódico CAPES em 23 maio de 2020. Fonte: Autores.

\footnotetext{
1 Ao colocar o termo "Chana com chana" (separado) na busca da plataforma Scielo, três artigos foram encontrados. Todos são da área da saúde e possuem autores(as) com o sobrenome "Chana". Logo não há relação com o que será trabalhado nesta pesquisa.
} 
Quadro 2 - Teses e Dissertações encontrados na plataforma BDTD e resultados obtidos

\begin{tabular}{|c|c|c|}
\hline Termo de busca & Resultados & Tipo \\
\hline $\begin{array}{l}\text { Chanacomchana ou } \\
\text { Chana com Chana }^{2}\end{array}$ & 01 & Tese \\
\hline \multirow[t]{2}{*}{ Lampião da Esquina } & 19 & 05 Teses \\
\hline & & 14 Dissertações \\
\hline
\end{tabular}

Pesquisas realizadas nas plataformas Scielo e Periódico CAPES em 23 maio de 2020. Fonte: Autores.

Quadro 3 - Artigos encontrados no SCIELO.

\begin{tabular}{|c|c|c|c|c|c|}
\hline $\mathbf{n}^{\mathbf{0}}$ & Tipo & Termo de busca & Título & Autor(a) & Ano \\
\hline 1 & Artigo & Lampião da Esquina & $\begin{array}{c}\text { Homossexualidades de papel: cenas } \\
\text { da imprensa homoerótica no Brasil } \\
(1963-2015)\end{array}$ & $\begin{array}{c}\text { José Miguel Arias } \\
\text { Neto e Muriel Emídio } \\
\text { Pessoa Do Amaral }\end{array}$ & 2016 \\
\hline 2 & Artigo & Lampião da Esquina & $\begin{array}{c}\text { Homofobia e os socialistas brasileiros } \\
\text { em "O Lampião da Esquina" (1978- } \\
1981)\end{array}$ & $\begin{array}{c}\text { Rodrigo Otávio } \\
\text { Moretti-Pires }\end{array}$ & 2018 \\
\hline 3 & Artigo & Lampião da Esquina & $\begin{array}{c}\text { Libertação gay no Brasil: discursos e } \\
\text { Esfrentamentos do jornal Lampião da durante a abertura política } \\
\text { (1978-1981) }\end{array}$ & $\begin{array}{c}\text { Ferreira Silva Júnior } \\
\text { Carlos Humberto }\end{array}$ & 2019 \\
\hline 4 & Artigo & Lampião da Esquina & $\begin{array}{c}\text { F desejo homossexual após a AIDS: } \\
\text { uma análise sobre os critérios } \\
\text { acionados por homens na busca por } \\
\text { parceiros do mesmo sexo }\end{array}$ & $\begin{array}{c}\text { João Paulo Ferreira e } \\
\text { Richard Miskolci }\end{array}$ & 2020 \\
\hline
\end{tabular}

Pesquisas realizadas nas plataformas Scielo e Periódico CAPES em 23 maio de 2020. Fonte: Autores.

Quadro 4 - Artigos encontrados no Periódicos CAPEs.

\begin{tabular}{|c|c|c|c|c|c|}
\hline $\mathbf{n}^{\mathbf{0}}$ & Tipo & Termo de busca & Título & Autor(a) & Ano \\
\hline 1 & Artigo & Lampião da Esquina & $\begin{array}{c}\text { Resposta à aids no Brasil: } \\
\text { contribuições dos movimentos sociais } \\
\text { e da reforma sanitária }\end{array}$ & $\begin{array}{c}\text { Alexandre Grangeiro, } \\
\text { Lindinalva Laurindo } \\
\text { da Silva e Paulo } \\
\text { Roberto Teixeira }\end{array}$ & 2009 \\
\hline 2 & Artigo & Lampião da Esquina & $\begin{array}{r}\text { Impressões de 1968: contracultura e } \\
\text { identidades }\end{array}$ & Cauê Krüger & 2010 \\
\hline 3 & Artigo & Lampião da Esquina & $\begin{array}{c}\text { O discurso homoerótico na imprensa } \\
\text { alternativa da década de setenta: uma } \\
\text { análise do "Lampião da Esquina" }\end{array}$ & Atilio Butturi Junior & 2012 \\
\hline 4 & Artigo & Lampião da Esquina & $\begin{array}{c}\text { Direitos Humanos em perspectiva } \\
\text { decolonial: por um direito inclusivo } \\
\text { da sexualidade }\end{array}$ & $\begin{array}{c}\text { Isabella Bruna Lemes } \\
\text { Pereira e Douglas } \\
\text { Antônio Rocha }\end{array}$ & 2016 \\
\hline
\end{tabular}

2 O termo "Chana com chana" (separado) suscitou na busca da plataforma do BDTD o encontro de 242 teses e dissertações. No entanto, ao ser analisado pelo título de cada um desses referidos trabalhos foi constatado que nenhum tinha relação com a revista analisada nesta pesquisa. 
Research, Society and Development, v. 10, n. 3, e18010313233, 2021

(CC BY 4.0) | ISSN 2525-3409 | DOI: http://dx.doi.org/10.33448/rsd-v10i3.13233

\begin{tabular}{|c|c|c|c|c|c|}
\hline & & & & Pinheiro & \\
\hline 5 & Artigo & Lampião da Esquina & $\begin{array}{c}\text { Militância homossexual no Brasil da } \\
\text { Ditadura Militar: os casos de João } \\
\text { Silvério Trevisan e João Antônio } \\
\text { Mascarenhas }\end{array}$ & $\begin{array}{l}\text { Paulo Roberto Souto } \\
\text { Maior Jr. e Miguel } \\
\text { Zioli }\end{array}$ & 2016 \\
\hline 6 & Artigo & Lampião da Esquina & $\begin{array}{c}\text { Escrever para inscrever-se: } \\
\text { epistolografia homossexual nas } \\
\text { páginas do Lampião da Esquina } \\
\text { (1978-1981) }\end{array}$ & $\begin{array}{l}\text { Paulo Roberto Souto } \\
\text { Maior Júnior }\end{array}$ & 2016 \\
\hline 7 & Artigo & Lampião da Esquina & $\begin{array}{c}\text { História das emoções, epistolografia e } \\
\text { homossexualidades no Brasil: “(...) } \\
\text { vocês falam pela minha garganta } \\
\text { muda” }\end{array}$ & $\begin{array}{l}\text { Paulo Roberto Souto } \\
\text { Maior }\end{array}$ & 2016 \\
\hline 8 & Artigo & Lampião da Esquina & $\begin{array}{c}\text { Folkcomunicação e Estudos de } \\
\text { Gênero: práticas de comunicação nos } \\
\text { grupos homossexuais }\end{array}$ & $\begin{array}{c}\text { Karina Janz } \\
\text { Woitowicz e } \\
\text { Guilherme Moreira } \\
\text { Fernandes }\end{array}$ & 2017 \\
\hline 9 & Artigo & Lampião da Esquina & $\begin{array}{l}26 \text { anos de REF: trouxemos as } \\
\text { chaves? }\end{array}$ & $\begin{array}{l}\text { Bruna Macedo } \\
\text { Goulart }\end{array}$ & 2018 \\
\hline 10 & Artigo & Lampião da Esquina & $\begin{array}{l}\text { Internacionais e glamorosas: sobre a } \\
\text { carreira das "travestis profissionais" }\end{array}$ & $\begin{array}{l}\text { Thiago Barcelos } \\
\text { Soliva }\end{array}$ & 2018 \\
\hline 11 & Artigo & Lampião da Esquina & $\begin{array}{l}\text { Sexualidade homossexual no jornal } \\
\text { Lampião da Esquina }\end{array}$ & $\begin{array}{l}\text { Natanael de Freitas } \\
\text { Silva e Natam Felipe } \\
\text { de Assis Rubio }\end{array}$ & 2018 \\
\hline 12 & Artigo & Lampião da Esquina & $\begin{array}{l}\text { Parte II - A construção da igualdade - } \\
\text { O Jornal Lampião da Esquina }\end{array}$ & Edward MacRae & 2018 \\
\hline 13 & Artigo & Lampião da Esquina & $\begin{array}{c}\text { La costruzione dell'identità } \\
\text { omosessuale in Brasile. O lampião da } \\
\text { esquina }\end{array}$ & Nicolò Pezzolo & 2018 \\
\hline 14 & Artigo & Chanacomchana & $\begin{array}{c}\text { Quebrando o Tabu: Visibilidade } \\
\text { lésbica através dos boletins } \\
\text { Chanacomchana }\end{array}$ & Larissa Pinto Martins & 2019 \\
\hline 15 & Artigo & Lampião da Esquina & $\begin{array}{l}\text { Bichas inauguram a utopia: } \\
\text { resistência homoerótica na literatura } \\
\text { lampiônica }\end{array}$ & $\begin{array}{l}\text { Ricardo Afonso- } \\
\text { Rocha e André Luís } \\
\text { Mitidieri }\end{array}$ & 2019 \\
\hline 16 & Artigo & Lampião da Esquina & $\begin{array}{c}\text { O desejo homossexual após a AIDS: } \\
\text { uma análise sobre os critérios } \\
\text { acionados por homens na busca por } \\
\text { parceiros do mesmo sexo }\end{array}$ & $\begin{array}{l}\text { João Paulo Ferreira e } \\
\text { Richard Miskolci }\end{array}$ & 2020 \\
\hline
\end{tabular}

Pesquisas realizadas nas plataformas Scielo e Periódico CAPES em 23 maio de 2020. Fonte: Autores. 
Quadro 5 - Teses e dissertações encontradas no BDTD.

\begin{tabular}{|c|c|c|c|c|c|}
\hline $\mathbf{n}^{\mathbf{o}}$ & Tipo & Termo de busca & Título & Autor(a) & Ano \\
\hline 1 & Tese & Lampião da Esquina & $\begin{array}{l}\text { SERÁ QUE ELE É?: Sobre } \\
\text { quando Lampião da Esquina } \\
\text { colocou as Cartas na Mesa }\end{array}$ & $\begin{array}{l}\text { Marcio Leopoldo } \\
\text { Gomes Bandeira }\end{array}$ & 2006 \\
\hline 2 & Dissertação & Lampião da Esquina & $\begin{array}{l}\text { A AIDS em cena: Os primeiros } \\
\text { protagonistas da maior epidemia } \\
\text { do final do século XX }\end{array}$ & $\begin{array}{c}\text { Gabriel Natal } \\
\text { Botelho Vitiello }\end{array}$ & 2009 \\
\hline 3 & Dissertação & Lampião da Esquina & $\begin{array}{l}\text { De Daniele a Chrysóstomo: } \\
\text { quando travestis bonecas e } \\
\text { homossexuais entram em cena }\end{array}$ & $\begin{array}{c}\text { Rita de Cássia } \\
\text { Colaço Rodrigues }\end{array}$ & 2012 \\
\hline 4 & Dissertação & Lampião da Esquina & $\begin{array}{c}\text { Representação do Corpo } \\
\text { Masculino: relações de imagem, } \\
\text { identidade e cultura sobre o corpo } \\
\text { masculino no jornal Lampião da } \\
\text { Esquina e na revista Junior }\end{array}$ & $\begin{array}{l}\text { Muriel Emídio } \\
\text { Pessoa do Amaral }\end{array}$ & 2013 \\
\hline 5 & Dissertação & Lampião da Esquina & $\begin{array}{l}\text { Amor feijão abaixo camburão - } \\
\text { Imprensa violência e trottoir em } \\
\text { São Paulo 1979-1983 }\end{array}$ & $\begin{array}{c}\text { Rafael Freitas } \\
\text { Ocanha }\end{array}$ & 2014 \\
\hline 6 & Dissertação & Lampião da Esquina & $\begin{array}{c}\text { Linhas e entrelinhas - } \\
\text { homossexualidades categorias e } \\
\text { políticas sexuais e de gênero nos } \\
\text { discursos da imprensa gay } \\
\text { brasileira }\end{array}$ & $\begin{array}{l}\text { Ricardo Augusto de } \\
\text { Sabóia Feitosa }\end{array}$ & 2014 \\
\hline 7 & Dissertação & Lampião da Esquina & $\begin{array}{c}\text { O Lampião da Esquina: Uma voz } \\
\text { homossexual no Brasil em tempos } \\
\text { de fúria (1978-1981) }\end{array}$ & $\begin{array}{l}\text { Alexandre Magno } \\
\text { Maciel Costa e } \\
\text { Brito }\end{array}$ & 2016 \\
\hline 8 & Dissertação & Lampião da Esquina & $\begin{array}{c}\text { "Flores horizontais": } \\
\text { Sociabilidade, prostituição e } \\
\text { travestilidade na Zona do Mangue } \\
(1960-1970)\end{array}$ & $\begin{array}{l}\text { Claudielle Pavão da } \\
\text { Silva }\end{array}$ & 2016 \\
\hline 9 & Dissertação & Lampião da Esquina & $\begin{array}{c}\text { Desejos comodificados: dos } \\
\text { classificados aos perfis nos } \\
\text { aplicativos na busca por parceiros } \\
\text { do mesmo sexo }\end{array}$ & $\begin{array}{c}\text { João Paulo Ferreira } \\
\text { da Silva }\end{array}$ & 2017 \\
\hline 10 & Dissertação & Lampião da Esquina & $\begin{array}{c}\text { "Gay-macho", "travesti" ou } \\
\text { "bicha pintosa"? - A produção } \\
\text { discursiva sobre representações } \\
\text { homoeróticas no Jornal Lampião } \\
\text { da Esquina (1978-1981) }\end{array}$ & $\begin{array}{c}\text { Ronielyssom Cezar } \\
\text { Souza Pereira }\end{array}$ & 2017 \\
\hline 11 & Dissertação & Lampião da Esquina & $\begin{array}{l}\text { AS POROSIDADES DO } \\
\text { TEMPO: velhos e velhices nas } \\
\text { publicações homoeróticas }\end{array}$ & $\begin{array}{c}\text { Fábio Ronaldo da } \\
\text { Silva }\end{array}$ & 2017 \\
\hline
\end{tabular}




\begin{tabular}{|c|c|c|c|c|c|}
\hline & & & brasileiras (1978-2013) & & \\
\hline 12 & Tese & Lampião da Esquina & $\begin{array}{c}\text { DZI CROQUETTES: Invenções, } \\
\text { experiências e práticas de si- } \\
\text { masculinidades e feminilidades } \\
\text { vigiadas }\end{array}$ & $\begin{array}{c}\text { Natanael de Freitas } \\
\text { Silva }\end{array}$ & 2017 \\
\hline 13 & Tese & Lampião da Esquina & $\begin{array}{c}\text { Uma bicha atrevida pede a } \\
\text { palavra: o Lampião da Esquina e } \\
\text { a resistência de homossexuais } \\
\text { durante a ditadura civil militar } \\
\text { brasileira }\end{array}$ & $\begin{array}{c}\text { Rogério Reis dos } \\
\text { Santos }\end{array}$ & 2017 \\
\hline 14 & Tese & Lampião da Esquina & $\begin{array}{l}\text { Contra a moral e os bons } \\
\text { costumes: A política sexual da } \\
\text { ditadura brasileira (1964-1988) }\end{array}$ & $\begin{array}{c}\text { Renan Honório } \\
\text { Quinalha }\end{array}$ & 2017 \\
\hline 15 & Tese & Chanacomchana & $\begin{array}{l}\text { Militância ou profissionalização } \\
\text { de gênero? Um estudo } \\
\text { comparativo na imprensa } \\
\text { feminista do Brasil, da Argentina } \\
\text { e do Chile (1981-1996) }\end{array}$ & $\begin{array}{c}\text { Júlia Glaciela da } \\
\text { Silva Oliveira }\end{array}$ & 2019 \\
\hline 16 & Dissertação & Lampião da Esquina & $\begin{array}{c}\text { "Lampião da Esquina", um jornal } \\
\text { alternativo do Brasil: iluminando } \\
\text { identidade(s) e } \\
\text { representação(ções) do(s) } \\
\text { homossexual(is) de 1978-1981 }\end{array}$ & $\begin{array}{c}\text { Geovane Batista da } \\
\text { Costa }\end{array}$ & 2019 \\
\hline 17 & Dissertação & Lampião da Esquina & $\begin{array}{c}\text { Performance, porrada e purpurina: } \\
\text { histórias e memórias LGBT+ em } \\
\text { recentes documentários } \\
\text { brasileiros }\end{array}$ & $\begin{array}{c}\text { Marcelo Saldanha } \\
\text { das Neves }\end{array}$ & 2019 \\
\hline 18 & Dissertação & Lampião da Esquina & $\begin{array}{c}\text { Qual é a tua, oh Lampião? } \\
\text { Tensionamentos em um jornal } \\
\text { editado na e pela Esquina }\end{array}$ & $\begin{array}{c}\text { João Lúcio Mariano } \\
\text { Cruz }\end{array}$ & 2019 \\
\hline 19 & Dissertação & Lampião da Esquina & $\begin{array}{l}\text { Ditos sobre e ditos por: o rasgo } \\
\text { afetivo das mulheres trans nos } \\
\text { discursos midiáticos }\end{array}$ & $\begin{array}{c}\text { Daniela de Queiroz } \\
\text { Picchiai }\end{array}$ & 2019 \\
\hline 20 & Tese & Lampião da Esquina & $\begin{array}{c}\text { OS HOMENS QUE SE } \\
\text { CUIDEM: O Sexo dos homens na } \\
\text { literatura brasileira a partir de } \\
\text { Aguinaldo Silva }\end{array}$ & $\begin{array}{c}\text { Eron Rafael dos } \\
\text { Santos }\end{array}$ & 2019 \\
\hline
\end{tabular}

Pesquisas realizadas nas plataformas Scielo e Periódico CAPES em 23 maio de 2020. Fonte: Autores.

No que diz respeito à produção por ano de publicação, percebe-se que entre 2006 e 2015 apenas 09 pesquisas relacionadas aos jornais Chanacomchana e Lampião da Esquina foram realizadas, ou seja, uma média de uma por ano. Entre 2016 e 2020 esse número aumentou significativamente, um total de 31, logo, uma média de quase 08 estudos anuais sobre os periódicos. De modo geral, pode-se afirmar que, após a distribuição temporal dos artigos, teses e dissertações encontrados, há 
uma maior concentração de produção de pesquisas que se relacionam aos periódicos estudados a partir do ano de 2016.

Depois de realizada a pesquisa quantitativa, a partir dos termos já citados, que resultou em 40 resultados, foi realizada a leitura dos resumos, palavras-chave e, quando necessária, consulta do texto para que pudesse haver uma filtragem do material levantado.

Feita uma primeira triagem, foram descartadas três pesquisas científicas, pois, em um dos casos, tratava-se de uma mesma publicação que está hospedada em diferentes plataformas. Sobre os outros dois textos, um não faz menção a qualquer dos jornais analisados e o outro cita apenas o título de uma pesquisa que analisa o Lampião da Esquina. Desse modo, esta análise segue com 37 pesquisas acadêmicas para categorização. As categorias apresentadas não foram definidas a priori, mas a medida em que as leituras e análises dos textos foram realizadas.

Os documentos selecionados foram divididos em 2 categorias principais que determinam a qual jornal a pesquisa científica se relaciona e, a partir destas, utiliza-se subcategorias para apresentar a abordagem e tratamento dados aos periódicos enquanto objeto de apreciação. A categoria I traz as pesquisas relacionadas ao jornal Lampião da Esquina e a categoria II concentrará os estudos ligados ao jornal ChanacomChana.

\section{Categoria I - Pesquisas científicas que estabelecem algum tipo de diálogo com o jornal Lampião da Esquina}

Entre os 38 estudos a serem categorizados, 36 estabelecem vínculo com o Lampião da Esquina. As abordagens escolhidas variam desde a menção ao jornal até a utilização do mesmo enquanto corpus do estudo.

\section{Corpus da pesquisa}

Dos textos selecionados para categorização, um grande número utiliza o jornal enquanto corpus da análise, 27 ao todo.

A abordagem realizada frente ao corpus, Lampião da Esquina, em 10 dos casos, é pensada de forma comparativa, ou seja, relaciona a outros periódicos de temática semelhante, documentos, entrevistas ou aplicativos utilizados décadas após a circulação do jornal. Esses estudos são compostos por 02 artigos científicos, 07 dissertações e 01 tese de doutoramento.

Outros 17 estudos utilizam-se, essencialmente, do Lampião da Esquina enquanto objeto de análise. A riqueza documental do periódico permite observar, nas diferentes pesquisas, as mais variadas abordagens e investigações, que se distribuem em 10 artigos científicos, 05 dissertações de mestrado e 02 teses de doutorado.

São abordadas nas pesquisas, questões como a representação do corpo masculino, visibilidade homossexual, identidade homossexual, resistência frente à ditadura civil e militar, veículo alternativo de imprensa para defesa dos interesses das comunidades LGBT, análise dos discursos das mulheres travestis e transexuais etc.

Cerca de $70 \%$ dos estudos que utilizam o Lampião da Esquina como corpus têm em sua abordagem o registro da importância política do periódico para aquele grupo, ainda que não seja, em alguns casos, enfatizada de forma pormenorizada.

Uma das seções mais exploradas do jornal é nomeada de "Cartas na mesa", um espaço para que os leitores possam registrar suas histórias, anseios e frustrações diante da realidade opressiva e incerta que enfrentavam. Dos 27 estudos, 06 têm essas cartas como ponto a ser explorado de forma minuciosa, sobretudo no que se refere a subjetividade daqueles que a enviam e suas preocupações no entorno de se assumir homossexual, (des)construção das representações homossexuais etc.

\section{Citações diretas retiradas do jornal Lampião da Esquina}

Do total de pesquisas levantadas neste estudo, 05 análises fazem citações diretamente retiradas de o Lampião da Esquina, todas expressando a importância da sua criação no que se refere à visibilidade homossexual e resistência durante o período da ditadura civil e militar do Brasil. Três dessas publicações utilizam-se de passagens do jornal para reforçar a sua 
importância enquanto veículo de visibilidade para a comunidade LGBT. Um dos estudos faz menção desse papel para estabelecer um vínculo com o documentário homônimo, foco daquela discussão, e o outro destaca algumas entrevistas dadas por travestis da época que se tornaram profissionais.

\section{Menção à existência do jornal Lampião da Esquina}

Outros 03 estudos fazem menção a criação e existência do jornal Lampião da Esquina enquanto símbolo da resistência LGBT no período da ditadura civil e militar e o estabelecem como um marco para na luta pela visibilidade dos homossexuais. Ainda que a menção seja breve, todas as pesquisas levantadas colocam-no na posição de imprensa alternativa de fundamental importância para a população homossexual que vive no período da ditadura civil e militar do Brasil.

\section{Categoria II - Pesquisas científicas que estabelecem algum tipo de diálogo com o jornal ChanacomChana}

Das 40 produções apresentadas apenas 02 retornaram após as buscas em que foram utilizados os termos "ChanacomChana" e "Chana com Chana"3. Esses dois trabalhos foram escritos por mulheres, as pesquisadoras Larissa Pinto Martins e Júlia Glaciela da Silva Oliveira. Ao observar a escassez das produções sobre um jornal de resistência lésbica, como é o caso do ChanacomChana, acende-se um alerta para a permanência da invisibilidade da história do movimento lésbico brasileiro, também na área de pesquisas contemporâneas.

Os dois estudos se dividem em uma tese de doutoramento e um artigo científico, ambos publicados no ano de 2019. Em suas análises apresentam o tratamento dado, pelos editoriais, à visibilidade lésbica. A tese se detém em um estudo comparativo entre publicações de três países da América Latina, Brasil, Argentina e Chile, durante as décadas de 1980 e 1990. Essas análises buscam as semelhanças e desacordos entre os diferentes projetos editoriais e como os mesmos impactaram, ou não, na militância feminista, ainda que não tenha havido homogeneidade dentro desse movimento.

O segundo analisa a representatividade/visibilidade da mulher lésbica a partir de questões como a maternidade, enrustimento e relações familiares tão caras a esse público. O trabalho também observa as pautas e anseios das mulheres a partir de um recorte político que contempla a lesbianidade.

\section{Conclusão}

A partir dos levantamentos realizados neste estudo, que tanto o jornal Lampião da Esquina quanto o boletim ChanacomChana figuram como fontes documentais importantes para análise e exploração do processo de visibilidade, identidade e representação homossexual masculina, no caso do primeiro, e feminina, no boletim. Contudo, estranha-se o fato de haver, até o momento, um 'razoável', se comparado ao boletim, número de pesquisas científicas publicadas vinculadas ao primeiro e uma escassez no segundo caso. Outro dado que permite reflexão está na autoria dessas pesquisas.

Fazendo uma análise quanto ao número de produções encontradas no BDTD, 20 ao todo, apenas duas são de autoria feminina, duas teses e duas dissertações. Essa discrepância é mantida quando se observa os artigos do Periódico CAPES, entre 16 publicações encontramos 11 escritos, exclusivamente, por homens e 03 realizados com parcerias femininas e apenas 02 produzidos por mulheres. Na plataforma SCIELO, os 04 documentos são produções masculinas. De modo geral, pode-se dizer que $77,5 \%$ das publicações que fazem parte desta análise foram realizadas exclusivamente por homens. O restante, ou somente $22,5 \%$, foi pesquisada por mulheres ou possui autoria conjunta.

Outro dado interessante está no fato de que entre as 04 obras de autoria exclusivamente feminina, 02 delas estão entre

\footnotetext{
${ }^{3}$ Durante a revisão percebemos que os descritores e os bancos escolhidos retornaram apenas dois trabalhos, por isso fizemos uma busca mais ampla, como o site de busca Google, Google Scholar e as referências dos artigos analisados e conseguimos encontrar mais 5 trabalhos que não estavam nas bases ou que não possuíam os descritores usados na busca e por estarem fora da metodologia proposta não analisaremos nesse artigo.
} 
as obras que não se adequavam ao critério de categorização proposto por este estudo e não foram utilizadas. Contudo, elas têm como objeto de análise a figura feminina, sejam mulheres lésbicas, transsexuais ou travestis. Em cada uma dessas publicações a abordagem da figura feminina é levantada. Este estudo não objetiva relacionar as temáticas ao gênero do autor, pelo contrário, mas é interessante ressaltar que, no caso do levantamento dos dados deste trabalho, esse padrão pode ser observado.

Pensando no levantamento registrado neste estudo observa-se as diferentes linhas de discussão que podem ser estabelecidas dentro dos periódicos, Lampião da Esquina e ChanacomChana. Das muitas seções encontradas nos mesmos, opinião, poemas, charges, cartas, classificados etc., isso se pensarmos em partes do jornal em separado, há uma diversidade de possibilidades ainda não exploradas. Essa realidade acentua quando pensamos no boletim ChanacomChana, que conta com um número ainda escasso de estudos.

As pesquisas até aqui elencadas destacam esses periódicos como um instrumento de resistência, visibilidade e identidade para a população LGBT. Mostra, também, a movimentação assumida pelas mulheres lésbicas ao não se perceberem representadas dentro de um espaço formado por homens, ainda que fossem homens homossexuais que sofriam preconceitos devido a sua sexualidade e sistema político vigente. Esses periódicos mostram os caminhos percorridos, durante o final da década de 1970 e meados de 1980, para que os direitos fundamentais fossem assegurados à parcela da população que era negligenciada e lançada à margem da sociedade, sobretudo dentro de um regime que tinha como lema a defesa da moral e dos bons costumes.

Com a quantificação e categorização realizadas, essa pesquisa de levantamento bibliográfico evidencia a urgência no aprofundamento e ampliação das diversas possibilidades apresentadas pelos dois periódicos, principalmente, o ChanacomChana que ainda não tem as suas muitas seções colocadas como objeto de análise, como já aconteceu com algumas das seções do Lampião da Esquina. Este levantamento evidencia que o boletim, mesmo que se reconheça que foi capaz, assim como o Lampião da Esquina, de quebrar estereótipos e demonstrar que as pessoas LGBT podem assumir o papel que desejar na sociedade, seja como mãe, profissional etc. e formar famílias homoparentais, ainda é pouco estudado.

O estudo da totalidade desses importantes veículos de resistência é necessário para que não se perca os primeiros passos de uma trajetória pela garantia de direitos que se mantém até os dias atuais e, a partir das análises desses registros de identidade e visibilidade, possa-se entender um pouco mais acerca do caminho percorrido pelas minorias que buscavam voz a partir da imprensa alternativa.

É evidente as poucas pesquisas realizadas sobre as duas imprensas alternativas, por isso a importância de pesquisas de revisão narrativa, pois elas possibilitam a análise de como são e quais foram os objetos analisados. Novas pesquisas poderão ser realizadas a partir desse levantamento e um aprofundamento dos conteúdos veiculados no período podem revelar as formas de resistências e avanços na busca por direitos da população LGBT.

\section{Agradecimentos}

Agradecemos ao professor Luciano de Jesus Gonçalves pela leitura atenta e correções pertinentes.

\section{Referências}

Boletim Chanacomchana. (1987).

Brito, A. M. M. C. e. (2016). O Lampião da Esquina: Uma voz homossexual no Brasil em tempos de fúria (1978-1981) [Universidade de Brasília]. https://repositorio.unb.br/handle/10482/21357

Campos, N. C. (2014). A lesbianidade como resistência: a trajetória dos movimentos de lésbicas no Brasil - $1979-2001$ [Universidade do Estado do Rio de Janeiro]. http://ppfh.com.br/wp-content/uploads/2018/04/Dissertação-Núbia-Carla-Campos-PDF.pdf

Da Costa, G. B. (2019). "Lampião da esquina”, um jornal alternativo do Brasil: iluminando identidade(s) e representação(ções) do(s) homossexual(is) de 1978-89 [Universidade Federal de Juiz de Fora (UFJF)]. https://repositorio.ufjf.br/jspui/handle/ufjf/11268 
Research, Society and Development, v. 10, n. 3, e18010313233, 2021

(CC BY 4.0) | ISSN 2525-3409 | DOI: http://dx.doi.org/10.33448/rsd-v10i3.13233

Eddine, E. A. C. (2019). A psicologia, a educação e as homossexualidades: o normal e o patológico nas produções discursivas das revistas Boletim de Psicologia, Revista Brasileira de Psicanálise e Cadernos de Pesquisa nas décadas de 1970 e 1980 [Biblioteca Digital de Teses e Dissertações da Universidade de São Paulo]. https://doi.org/10.11606/T.48.2019.tde-11042019-121021

Falquet, J. (2012). Romper o tabu da heterossexualidade: contribuições da lesbianidade como movimento social e teoria política. Cadernos de Crítica Feminista, 6(5).

Ferreira, C. (2010). Imprensa Homossexual: surge o Lampião da Esquina. Revista Alterjor, 1(1). https://www.revistas.usp.br/alterjor/article/view/88195

Green, J. N., \& Quinalha, R. (2015). Homossexualidades, Repressão e Resistência durante a Ditadura. In Relatório da Comissão da Verdade do Rio de Janeiro (pp. 151-161). CEV-Rio.

Ire, B., Silva, C. D., \& Lenzi, M. H. (2019). Ser Lésbica na Ditadura: Vida e Militância sob Estado de Exceção. In C. S. Wolff, J. Zandoná, \& S. C. de MELLO (Eds.), Mulheres de Luta: feminismo e esquerdas no Brasil (1964-1985) (pp. 185-208). Appris.

Jornal Chanacomchana. (1981). GALF.

Jornal Lampião da Esquina. (1979).

Lessa, P. (2009). Visibilidade e ação lesbiana na década de 1980: uma análise a partir do grupo de ação lésbico-feminista e do Boletim Chanacomchana. Revista Gênero, 8(2), 301-334. https://doi.org/https://doi.org/10.22409/rg.v8i2.187

Lima, M. de F. E. M., \& Eddine, E. A. C. (2015). Homossexualidades: Espaço em uma revista especializada? Temas Em Psicologia, 23(3), 789-801. https://doi.org/10.9788/TP2015.3-21

MacRae, E. (2018). A construção da igualdade - politica e identidade homossexual no Brasil da "abertura." EDUFBA. https://repositorio.ufba.br/ri/handle/ri/27774

Moretti-Pires, R. O., Tesser Júnior, Z. C., \& Kovaleski, D. F. (2018). Homofobia e os socialistas brasileiros em “O Lampião da Esquina” (1978-1981). Revista Estudos Feministas, 26(3), 1-13. https://doi.org/10.1590/1806-9584-2018v26n345989

Neto, J. M. A., \& Do Amaral, M. E. P. (2016). Homossexualidades de papel: Cenas da imprensa homoerótica no Brasil (1963-2015). Cuadernos.Info, 39, 101112. https://doi.org/10.7764/cdi.39.986

Oliveira, L. F. (2017). Quem tem medo de sapatão? Resistência lésbica à Ditadura Militar (1964-1985). Revista Periódicus, 1(7), 06. https://doi.org/10.9771/peri.v1i7.21694

Pereira, A. S., Shitsuka, D. M., Parreira, F. J., \& Shitsuka, R. (2018). Metodologia da pesquisa científica. UFSM. https://repositorio.ufsm.br/bitstream/ha ndle/1/15824/Lic_Computacao_Metodologia-Pesquisa-Cientifica.pdf?sequence=1.

Sales, G. C. (2019). Lésbicas no debate da redemocratização: uma análise do Boletim Chanacomchana [Universidade de Brasília]. https://bdm.unb.br/handle/10483/22879 